\title{
Design of Smart Fuzzy Logic Controller in Quad Buck-Boost DC-DC Converter with Constant Input and Output Current
}

\author{
Lahari S, Dhanalakshmi R
}

\begin{abstract}
In this paper, the design of a fuzzy logic controller based quad buck-boost converter with constant input and output current is presented. In contrast with the ordinary step-down-up converters the advanced converter with same duty cycle, a large limit of voltage conversion ratio could be acquired. A proposed converter is designed and studied with an intelligent controller i.e. fuzzy logic controller/FLC and differentiated with the ordinary Proportional-Integral /PIC controller. Finally, the analysis of the presented converter by employing MATLAB/Simulink, simulation results of the presented converter is recorded to substantiate the effectualness and rationality of the output voltage control of Quad buck-boost converter in both step-down-up mode and its comparative analysis is presented where the fuzzy logic has a minimum overshoot and settling time compared to regular PI controller.
\end{abstract}

Keywords: constant input and output port current, PI controller (PIC), Fuzzy logic controller (FLC), Overshoot, Settling time.

\section{INTRODUCTION}

$\mathrm{N}$ owa was, with the elevation of the power electronic technology, awareness about the effects of exhaustible energy sources on the environment, the employment of inexhaustible energy sources has gained more importance as a future energy source. However, these alternative energy systems will have an output whose voltage is variable, depending on various environmental conditions. For achieving the better performance, DC-DC converters are employed in the inexhaustible energy sources to match the load demand. With the wield of inexhaustible energy sources the manufacturing cost is reduced. It can be used in some of the applications such as PV- street lights, batteries/supercapacitors, power systems, solar planned applications, electric automobiles.Some of the associated works related to the quadratic converters where it has a quadratic relationship for the voltage conversion ratio in terms of duty its duty cycle where it can operate in an extensive range of $\mathrm{i} / \mathrm{p}$ output voltage conversion applications [1]-[3]. Plenty of studies has been flourished and described on quadratic buck converters where some investigations have been done on the mathematical modelling, methods of control [4]-[8] and quadratic boost converters where its novel topologies were analyzed [9]-[12]. But only a few investigations are done on quadratic buck-boost converters. By using these types of modified converters transformer isolation is optional.

Revised Manuscript Received on June 15, 2020.

* Correspondence Author

Lahari S*, Electrical and Electronics Engg, Dayananda sagar college of Engg, Bangalore, India. Email: laharisreddy95@gmail.com

Dr. Dhanalakshmi R, Electrical and Electronics Engineering, Dayananda Sagar College of Engineering, Bangalore, India. Email: dhanalakshmi-eee@dayanandasagar.edu

(c) The Authors. Published by Blue Eyes Intelligence Engineering and Sciences Publication (BEIESP). This is an open access article under the CC BY-NC-ND license (http://creativecommons.org/licenses/by-nc-nd/4.0/)
These converters are better structured, less expensive besides the regular quadratic step-up converter. Few groundworks on conventional quadratic buck-boost converters which is created by combining two conventional buck-boost converters where the input and output current is not continuous [13]-[14] and the application area where the converter can be used like energy stocking devices similarly batteries/supercapacitors with electrical, electrochemical principle is investigated [15].

Precise control is hard in every operation that leads to the utilization of various type of controllers which are being employed in many industries such as process industries. Different methods of regulations are very important for those industries.

To regulate the demand of load and to reduce the overshoot, settling time, with faster response a control technique is used for DC-DC converters. Different properties of the DC-DC converters could be explored using the closed loop control. A few groundworks are done on the approach for PI controllers to control the performance across various devices. And few of the approaches are regulation of current in PWM converters which are connected to the grid, stabilization of switched power converters and 1- $\emptyset$ grid associated converters are regulated for DC link voltage where the main aim was to cut down the swing of voltage in dc-link and to track load voltage accuracy of $\pm 0.05 \mathrm{~V}$ of a cuck converter [16]-[19]

As all controllers face the issues, error free modelling is hard, might be impractical in most cases. Normally controllers may not function properly for nonlinear systems hence the next approach was the use of smart/intelligent control systems such as FLC. The approach of FLC where it is compared with other controller such as PID for buck and boost DC-DC converters. Where FLC exhibits a cut above performance [20]. Fuzzy logic can control the various applications like the sensitiveness for fluctuating supply voltages and imbalance in the load resistance in SMPS (switch mode power stage) dc-dc converters, line regulation and load regulation, MPPT of a SEPIC converter with small-scale overshoot and steady state error, voltage tracking, regulation of DC motor which is separately excited [21]-[28]. However, the goal of this paper is to construct an intelligent control i.e. FLC to a quad buck boost converter and compare it with the analysis of the traditional PI controller. As these converters are widely used in applications such as PV-street lighting, batteries or supercapacitors, electric automobiles etc.

Blue Eyes Intelligence Engineering

\& Sciences Publication

(C) Copyright: All rights reserved. 
As input may vary hence there is need to control constant $\mathrm{o} / \mathrm{p}$ voltage therefore there is a great need to design the controllers. The problems such as overshoot and larger settling times are some of the problems faced by all control systems. Error-free modelling is hard, expensive and even impractical in most cases as the actual world systems are nonlinear. Typical controllers such as PI controllers and smart control systems such as fuzzy logic controllers or neural networks etc. are used. Normally traditional controllers like PI may not function correctly for non-linear systems, to conquer these problems Smart/intelligent control is used.

\section{CONVENTIONAL AND PROPOSED QUAD BUCK-BOOST CONVERTER}

Conventional quadratic buck-boost converter encounters increased input and output ripple currents with discontinuous input and output currents causing complexity in construction of $\mathrm{i} / \mathrm{p}$ and o/p filters [1]-[2]. The conventional converter is shown in the below Fig 1. It is formed by combining two ordinary step-down-up converters. As the $\mathrm{L}_{1}$ inductor current is alike to the $i / p$ current $i_{\text {in }}$ during turn on of switch, the $L_{2}$ inductor current is alike to the o/p current during switch turn off. Hence the input and output current is not continuous.

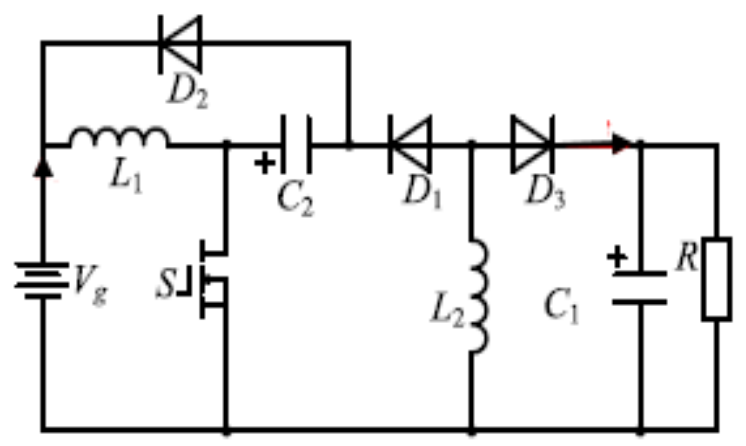

Fig 1: Conventional quadratic buck-boost converter

To get the better of the downside of conventional converter a novel quad buck-boost converter is preferred. Most of the industrial applications prefer a continuous inductor current mode. Fig 2 shows the proposed quad buck-boost converter which is union of a conventional boost, buck and buck-boost converter using single switch. The converter presented can operate in persistent mode of inductor current with a wider conversion ratio of voltages compared to conventional converter. This also resulted in the simplified design of filters.

\section{STATE SPACE ANALYSIS OF THE PROPOSED QUAD BUCK-BOOST CONVERTER}

In order to estimate the nonlinear system to liner SSA i.e. state space analysis is used. The small signal analysis of the quad buck-boost converter as in Fig 2 is obtained from state space analysis. The proposed converter can be divided into two intervals, Interval one during switch-on and interval 2 during switch-off. By considering the state space equations in each of these intervals and combining gives the final model representation. Here a constant conduction mode (CCM) is taken and few assumptions like all the components are ideal are taken into consideration.

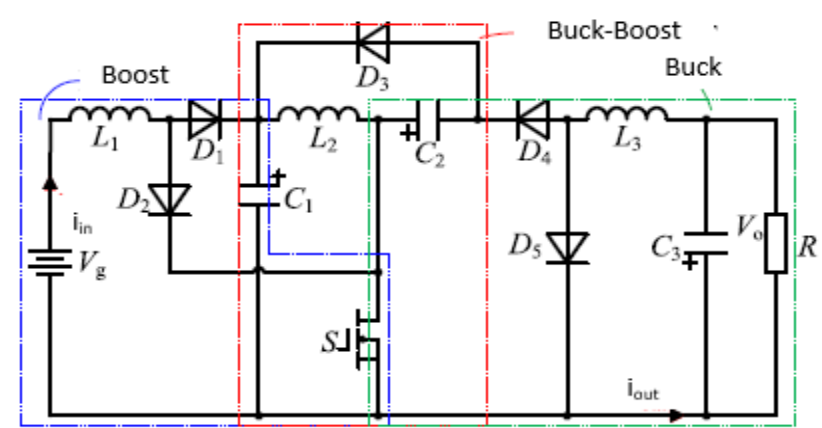

Fig 2: Proposed quad buck-boost converter

Interval 1: when switch is on at the time interval dt, the state space equation in its generic form is stated by

$X^{1}(t)=A_{1} X(t)+B_{1} U(t)$ Where $0<t<d t$

$Y(t)=C_{1} X(t)+D_{1} U(t)$ Where $0<t<d t$

The main equations of the storage components i.e. the inductor and capacitor when switch on in the interval dt in $\mathrm{CCM}$ is given by

$\frac{d_{i L 1}}{d t}=\frac{v g}{L 1}, \frac{d_{i L 2}}{d t}=\frac{V_{c 1}}{L 2}, \frac{d_{i L 3}}{d t}=\frac{V_{c 2}-V_{0}}{L 3}$

$\frac{d_{V c 1}}{d t}=\frac{i_{L 2}}{C_{1}}, \frac{d_{V c 2}}{d t}=\frac{i_{L 3}}{C_{2}}, \frac{d_{V 0}}{d t}=\frac{1}{C 3}\left(i_{l 3}-\frac{V_{0}}{R}\right)$

By referring to (3) and (4) we obtain the averaged matrices of the duration when switch is on

$$
\begin{aligned}
& \mathrm{A}_{1}=\left[\begin{array}{cccccc}
0 & 0 & 0 & 0 & 0 & 0 \\
0 & 0 & 0 & \frac{1}{L 2} & 0 & 0 \\
0 & 0 & 0 & 0 & \frac{1}{L 3} & \frac{-1}{L 3} \\
0 & \frac{1}{C 1} & 0 & 0 & 0 & 0 \\
0 & 0 & \frac{1}{C 2} & 0 & 0 & 0 \\
0 & 0 & \frac{1}{C 3} & 0 & 0 & \frac{-1}{R C_{3}}
\end{array}\right] \quad \mathrm{B}_{1}=\left[\begin{array}{c}
\frac{1}{L 1} \\
0 \\
0 \\
0 \\
0 \\
0
\end{array}\right] \\
& \mathrm{C}_{1}=\left[\begin{array}{llllll}
0 & 0 & \frac{-1}{L 3} & 0 & 0 & \frac{-1}{R C_{3}}
\end{array}\right] \quad \mathrm{D}_{1}=[0]
\end{aligned}
$$

Interval 2: when switch is off at the time interval (1-d)t, the space equation in its generic form is stated by

$X^{1}(t)=A_{2} X(t)+B_{2} U(t)$ Where $0<t<(1-d) t$
$Y(t)=C_{2} X(t)+D_{2} U(t)$ Where $0<t<(1-d) t$

The main equations of the storage components i.e. the inductors and capacitors when switch off in the interval (1-d)t in CCM is given by

$$
\begin{aligned}
& \frac{d_{i L 1}}{d t}=\frac{V g-V_{C 1}}{L 1}, \frac{d_{i L 2}}{d t}=\frac{-V_{c 2}}{L 2}, \frac{d_{i L 3}}{d t}=\frac{-V_{0}}{L 3} \\
& \frac{d_{V c 1}}{d t}=\frac{-i_{L 1}}{C_{1}}, \frac{d_{V c 2}}{d t}=\frac{-i_{L 2}}{C_{2}}, \frac{d_{V 0}}{d t}=\frac{1}{C 3}\left(i_{l 3}-\frac{V_{0}}{R}\right)
\end{aligned}
$$

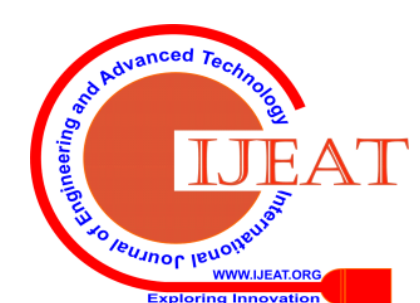


By referring to (8) and (9) we obtain the averaged matrices of the duration when switch is off

$\mathrm{A}_{2}=\left[\begin{array}{cccccc}0 & 0 & 0 & \frac{-1}{L 1} & 0 & 0 \\ 0 & 0 & 0 & 0 & \frac{-1}{L 2} & 0 \\ 0 & 0 & 0 & 0 & 0 & \frac{-1}{L 3} \\ \frac{-1}{C 1} & 0 & 0 & 0 & 0 & 0 \\ 0 & \frac{-1}{C 2} & 0 & 0 & 0 & 0 \\ 0 & 0 & \frac{1}{C 3} & 0 & 0 & \frac{-1}{R C_{3}}\end{array}\right] \quad \mathrm{B}_{2}=\left[\begin{array}{c}\frac{1}{L 1} \\ 0 \\ 0 \\ 0 \\ 0 \\ 0\end{array}\right]$

$\mathrm{C}_{2}=\left[\begin{array}{llllll}0 & 0 & \frac{-1}{L 3} & 0 & 0 & \frac{-1}{R C_{3}}\end{array}\right] \quad \mathrm{D}_{2}=[0]$

By referring (5) and (10) we get the averaged matrices during the interval switch on and off, the state space representation of the quad buck-boost converter is a combination of both intervals of switch and the given by

$$
\begin{aligned}
& X^{1}=\left[A_{1} d+A_{2}(1-d)\right] X+\left[B_{1} d+B_{2}(1-d)\right] \\
& Y=\left[C_{1} d+C_{2}(1-d)\right] X+\left[D_{1} d+D_{2}(1-d)\right] U
\end{aligned}
$$

Equation (5) and (10) is substituted in (11) and (12) to obtain the final matrix

$$
\mathrm{A}=\left[\begin{array}{cccccc}
0 & 0 & 0 & \frac{d-1}{L 1} & 0 & 0 \\
0 & 0 & 0 & \frac{d}{L 2} & \frac{d-1}{L 2} & 0 \\
0 & 0 & 0 & 0 & \frac{d}{L 3} & \frac{-1}{L 3} \\
\frac{d-1}{C 1} & \frac{d}{C 1} & 0 & 0 & 0 & 0 \\
0 & \frac{d-1}{C 2} & \frac{d}{C 2} & 0 & 0 & 0 \\
0 & 0 & \frac{1}{C 3} & 0 & 0 & \frac{-1}{R C_{3}}
\end{array}\right] \quad \mathrm{B}=\left[\begin{array}{c}
\frac{1}{L 1} \\
0 \\
0 \\
0 \\
0 \\
0
\end{array}\right]
$$

$\mathrm{C}=\left[\begin{array}{llllll}0 & 0 & \frac{-1}{L 3} & 0 & 0 & \frac{-1}{R C_{3}}\end{array}\right] \quad \mathrm{D}=[0]$

Transfer function of the plant is obtained by substituting (13) in (14) where $d$ is the duty cycle $L_{1}, L_{2}$ and $L_{3}$ are the inductors and $\mathrm{R}$ is the resistance and $\mathrm{C}_{1}, \mathrm{C}_{2}, \mathrm{C}_{3}$ are the capacitors.

$\frac{Y(s)}{U(s)}=C[S i-A]-1 B+D$

By considering the values from Table II according to its mode i.e. the step- up/down and substituting (13) in (14) we obtain

Transfer function of a plant in step-up mode:

$G_{p}($ boost $)=3600+\frac{15267.56}{0.0002 S+4.3897}$

Transfer function of a plant in step-down mode:

$G_{p}(b u c k)=210+\frac{1170.424}{0.0002 S+5.7207}$

\section{RPROPOSED QUAD BUCK-BOOST CONVERTER WITH DIFFERENT CONTROL TECHNIQUES}

Desired level of output voltage can be regulated by the employment of closed loop control thereby production of the system can be enhanced. With the help of this control techniques settling time and overshoot of the output voltage can be reduced.

\section{A. Conventional PI controller}

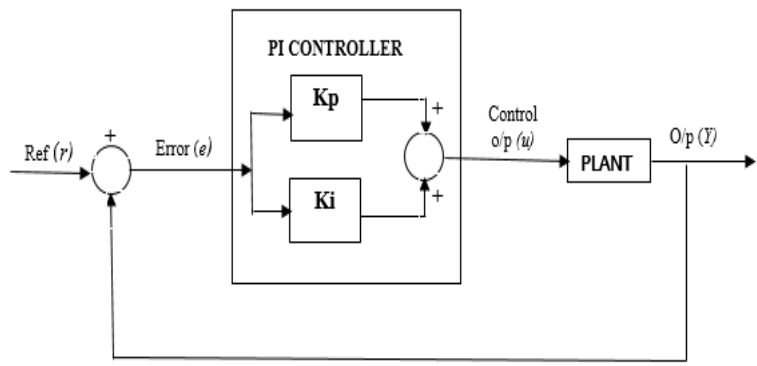

Fig 3: General PI Controller

PI controller is one among the closed loop control system without a manual input requirement. A closed loop control is group of devices that involuntarily regulates a process variable to a desired state. The Fig 3 indicates general PI controller design with a feedback loop. Here the output signal $Y$ is taken as a feedback and differentiated with the input reference signal $r$. Output signal is compared with the reference signal, error signal $e$ is generated and fed to the controller part, controller on obtaining the error signal applies a rectification based on the proportional $(\mathrm{Kp})$ and integral (Ki) terms. Control o/p $u$ is the summation of proportional gain and integral gain.

The PIC control equation is as follows

$U(s)=K_{p} E(s)+\frac{1}{s} K_{i} \int E(s)$

The quad buck-boost converter controlled by PI controller techniques and its results are compared with the proposed smart fuzzy logic control.

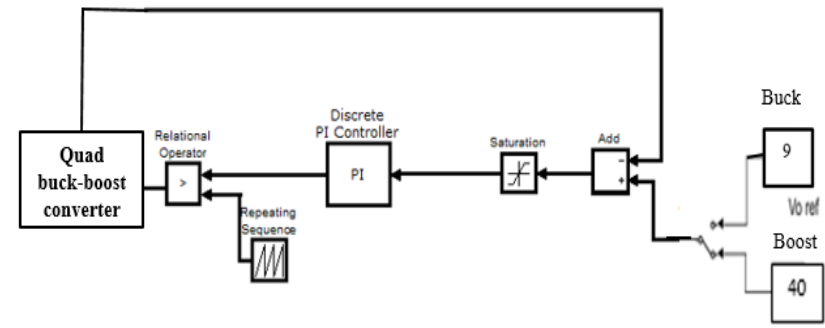

Fig 4: Quad buck-boost with PI Controller

Procedure of PI controlled converter is as follows: quad buck-boost converter output voltage is compared with the persistent value; the obtained error signal is fed to the saturation block. PI controller output is supplied to the relational operator where it is differentiated with the triangular pulses and the gate pulses are generated. The output of the relational operator is fed to the gate terminal of switch as in Fig 4. 


\section{B. Proposed Fuzzy Logic controller}

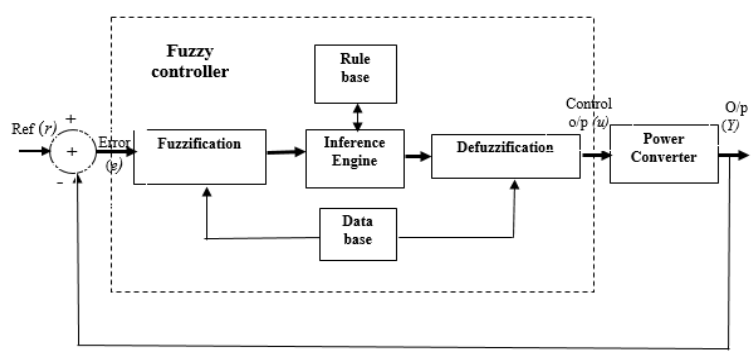

Fig 5: General Structure of Fuzzy Logic Controller

Smart/Fuzzy logic is a peculiar control system. Fuzzy reasoning is also known as FLC/fuzzy logic controller. It is implemented successfully in diverse applications like industries. It is a multivalent logic where mid values to be defined between estimations like true/false, high/low. Fuzzy logic is a way to make the devices more intelligent to make it reason like humans using fuzzy logics. This controller uses a very flexible set of if-then rules. This solution is further applied to the membership functions. The rule system has four modules in FLC as shown in the general structure of FLC as in Fig 5.

1. Fuzzification: It is an action of transforming a real number to a fuzzy number.

2. Rule base: An excellent evaluation of mandani is used for the rule base. It is formed in "IF-THEN" setup. Using this format rules are constructed for the output. In these format of formation rules IF is known for condition and THEN is known for conclusion.

3. Fuzzy Inference: A chart is constructed from the given input to an output by employing the fuzzy logic. This chart lays out a justification amid which the truth is elected.

4. Defuzzification: It is a process of producing a quantitate result in crisp logic. It converts fuzzy number to a real number. Two common methods in defuzzification is centroid and maximum.

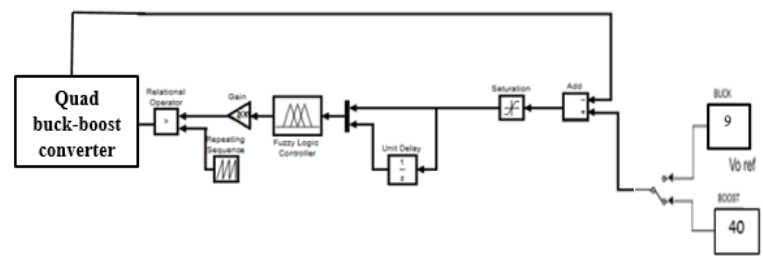

Fig 6: Quad buck-boost with Fuzzy logic Controller

- Design procedure for fuzzy logic controller:

In this paper a rule based FLC is applied to quad buck-boost converter as in Fig 6. Before the system is simulated in the MATLAB/SIMULINK a FLC has to be constructed. A FIS file is created in FIS editor using a fuzzy logic toolbox. Here a choice of membership functions is created, accordingly base for rules are created. Linguistic variables that are needed to create the rule base is logged in Table $\mathrm{I}$. The retaliation of a controller is obtained in the MATLAB/SIMULINK. The membership functions i.e. two inputs, an error, change in error and one output which is control change is created and 25 fuzzy rules are determined. Membership function and fuzzy rules are shown in Fig 7(a), 7(b), 7(c) and 8(a), 8(b).
- Membership Functions of the Fuzzy Logic controller

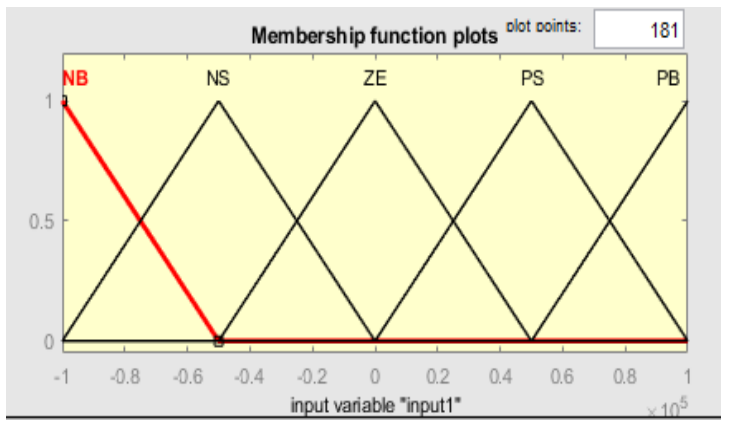

Fig 7(a): Fuzzy input 1 variable "error "

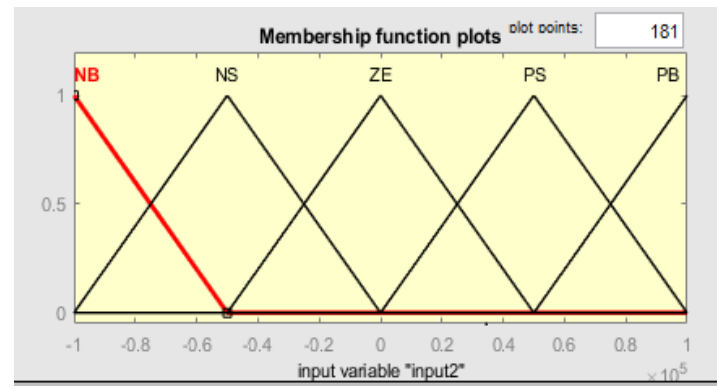

Figure 7(b): Fuzzy input 2 variable "change in error "

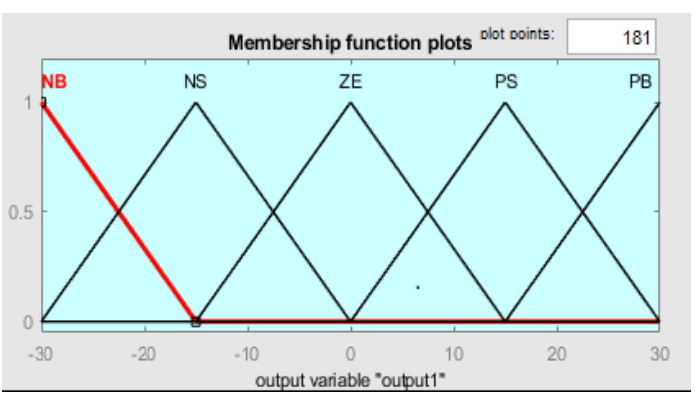

Fig 7(c): Fuzzy output variable "voltage control "

- Fuzzy inference rule set:

Table I: Rule table for output variable "control"

\begin{tabular}{|c|c|c|c|c|c|}
\hline Rules & NB & NS & ZE & PS & PB \\
\hline NB & NB & NB & PS & PB & PB \\
\hline NS & NB & NB & ZE & PB & PB \\
\hline ZE & NB & NS & ZE & PS & PB \\
\hline PS & NB & NB & ZE & PB & PB \\
\hline PB & NB & NB & NS & PB & PB \\
\hline
\end{tabular}

Where NB - Negative Big

NS - Negative Small

ZE - Zero

PS - Positive Small

PB - Positive Big

- Formation of rules and outlook of rule viewer:

In Fig 8(a) and 8(b) 25 set of IF-THEN rules are indicated, Fig 9 shows the study of inputs and an output i.e. error, change in error and control of output voltage.

Published By:

Blue Eyes Intelligence Engineering

\& Sciences Publication

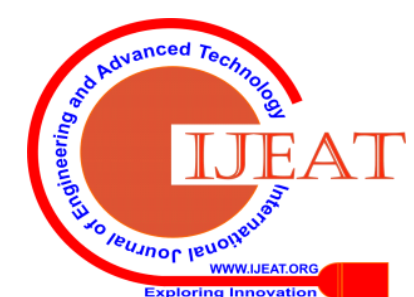




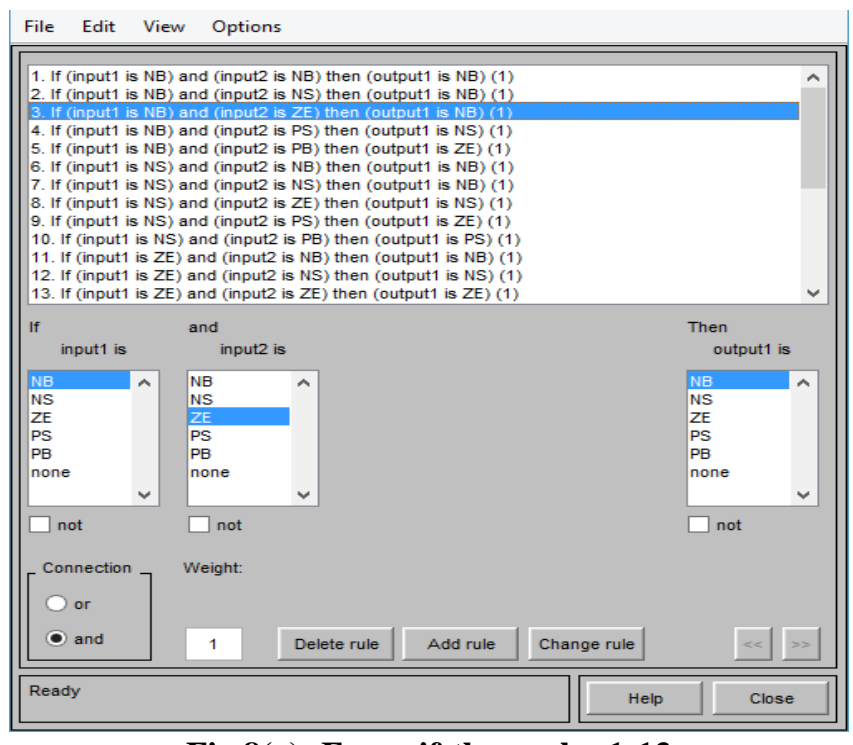

Fig 8(a): Fuzzy if-then rules 1-13

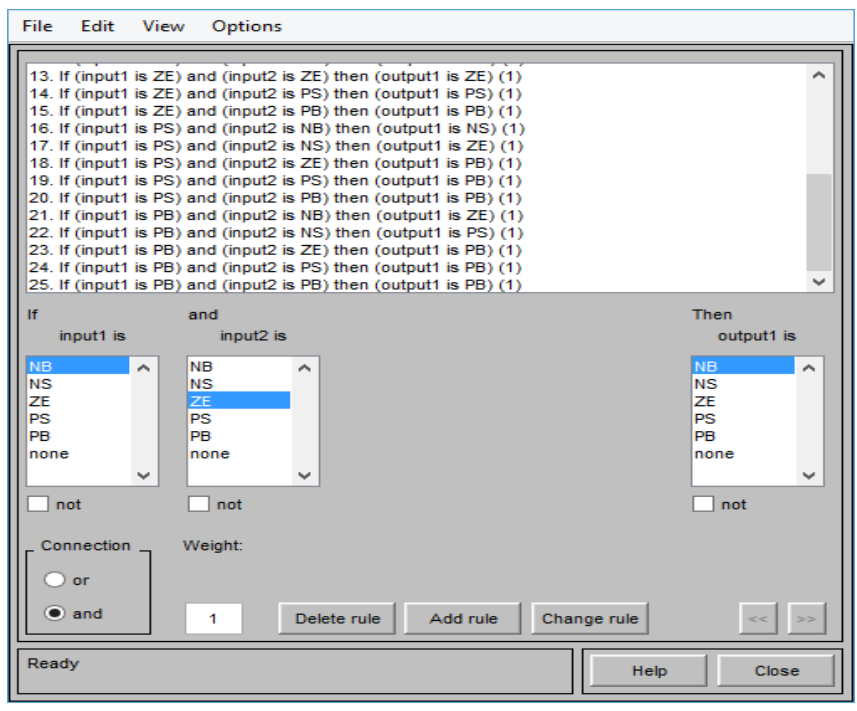

Fig 8(b): Fuzzy if-then rules 14-25

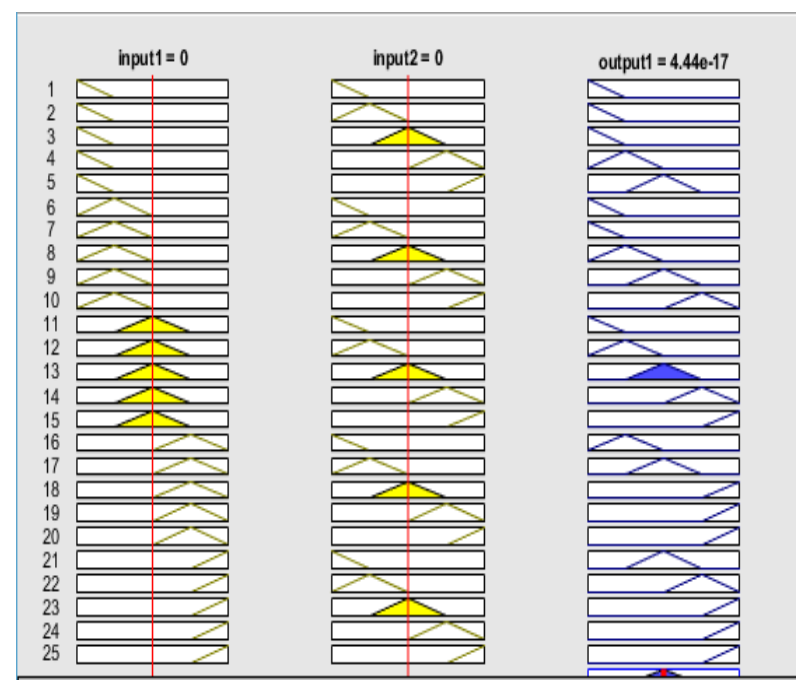

Fig 9: Analysis of both inputs and outputs

\section{MATLAB/SIMULINK IMPLEMENTAION, RESULTS AND DISCUSSION}

\section{A. Proposed converter with conventional PI controller}

Fig 10 shows the Simulink/MATLAB model of proposed quad buck-boost converter with PI controller for an input of 20v. The Kp and Ki values are obtained from Z-N method which is 0.001 and 3 The simulation variables are indicated in Table II.

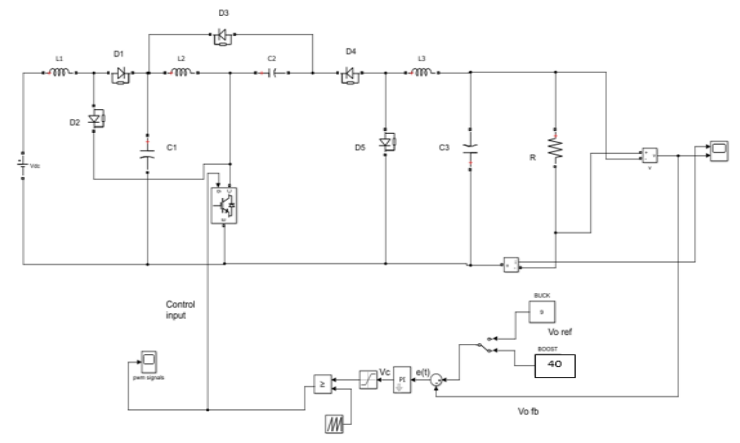

Fig 10: Simulation circuit of PI controlled Quad Buck-Boost Converter.

Table II: Simulation variables of the converter proposed.

\begin{tabular}{|c|c|}
\hline Input voltage (Vg) & $20 \mathrm{v}$ \\
\hline Output voltage (V0) & $40 \mathrm{~V}$ \\
[for step-up] & $9 \mathrm{~V}$ \\
[for step-down] & $100 \mu \mathrm{H}, 400 \mu \mathrm{H}, 3 \mathrm{mH}$ \\
\hline Inductor L1, L2, L3 & $47 \mathrm{e}-6 \mathrm{~F}$ \\
\hline Capacitors ( C1, C2) & $220 \mathrm{e}-6 \mathrm{~F}$ \\
\hline (C0) & $40 \mathrm{kHz}$ \\
\hline Switching frequency & $>50 \%$ \\
\hline Duty cycle [for Step-up] & $<50 \%$ \\
\hline [for Step-down] & $90 \Omega$ \\
\hline Resistance & \\
\hline
\end{tabular}

\section{B. Proposed converter with Fuzzy Logic controller}

Fig 11 indicates the Simulink/MATLAB model of quad buck-boost converter for an input of 20v with the proposed Fuzzy logic controller (FLC). The simulation variables are listed in Table II.

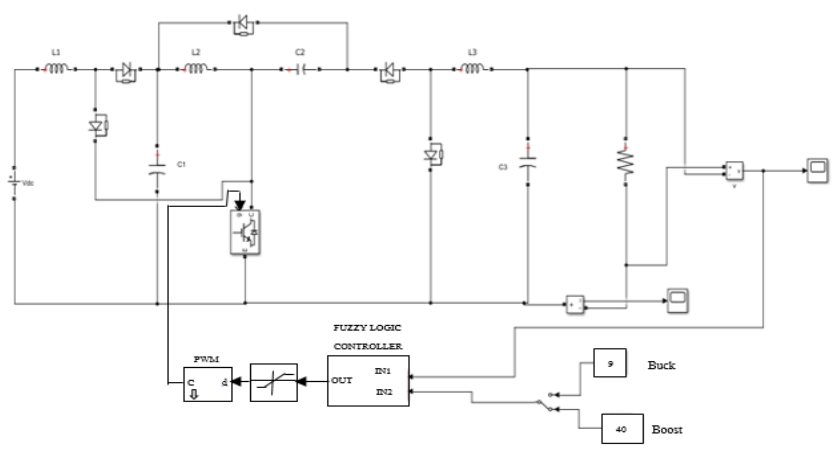

Fig 11: simulation circuit of FLC Quad Buck-Boost Converter

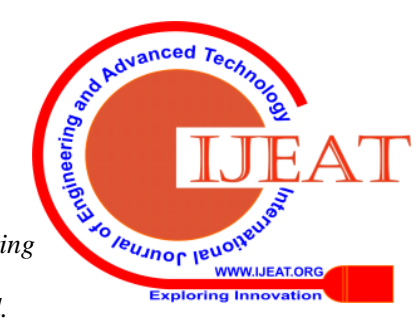




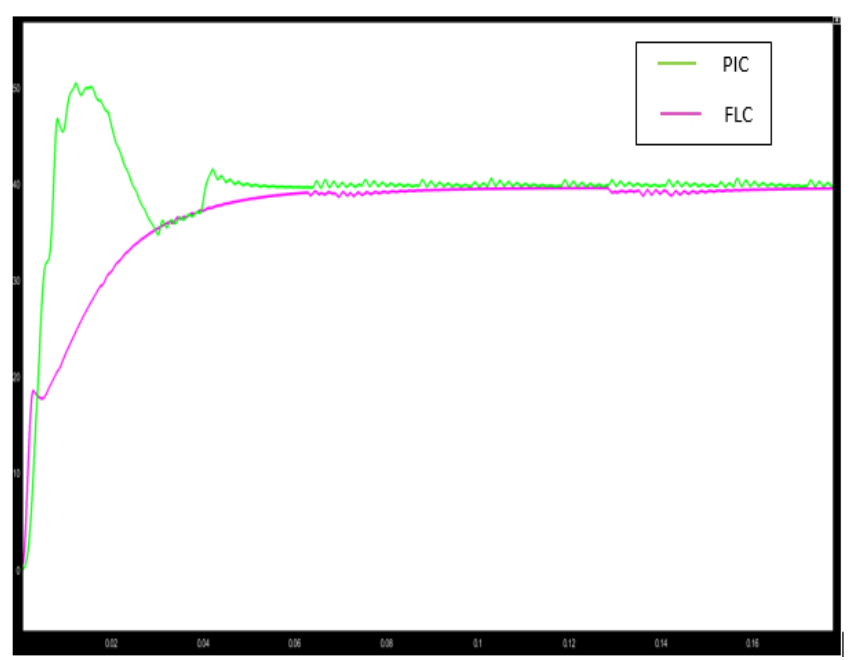

Fig 12: Comparison of o/p voltage Vo of Quad buck-boost converter in step-up mode with different control techniques.

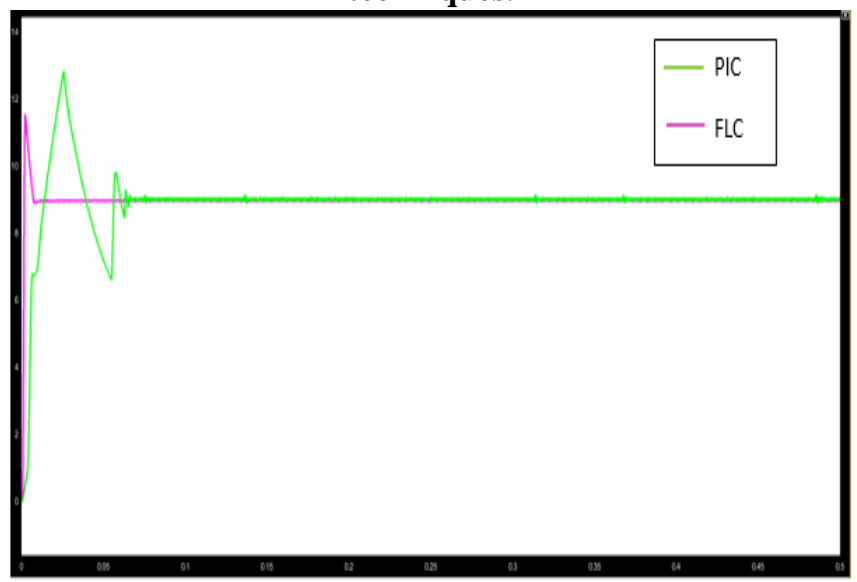

Fig 13: Comparison of o/p voltage Vo of Quad buck-boost converter in step-down mode with different control techniques.

\section{Comparison table of the response of controllers}

Table III and Table IV presents the comparison of proposed converter for two different closed loop controllers i.e. PI and Fuzzy logic controller in both step-up and step-down mode as indicated in the Fig 12 and Fig 13. It is noticed that fuzzy logic controlled Quad buck-boost converter gives the better performance than the conventional PI control with reduced overshoot and settling time.

Table III: Comparison table of the response of controllers in step-up mode

\begin{tabular}{|c|c|c|}
\hline Parameters & PIC & FLC \\
\hline Overshoot (\%) & $0.50 \%$ & $0.186 \%$ \\
\hline Settling time (s) & 0.04 & 0.003 \\
\hline
\end{tabular}

Table IV: comparison table of the response of controllers in step-down mode:

\begin{tabular}{|c|c|c|}
\hline Parameters & PIC & FLC \\
\hline Overshoot (\%) & $0.129 \%$ & $0.115 \%$ \\
\hline Settling time (s) & 0.06 & 0.008 \\
\hline
\end{tabular}

\section{CONCLUSION}

In this paper the output voltage of the proposed quad buck-boost converter along constant input, output current is controlled using FLC. The circuit is simulated in MATLAB/SIMULIK software to substantiate the circuit function. From the simulated results it is inferred that the given topology of Quad Buck-Boost converter produces a step-up output voltage up to $40 \mathrm{~V}$ for a given input of $20 \mathrm{~V}$ and a step-down output of 9V. The conventional control i.e. Proportional-Integral (PI) controller is differentiated from smart/intelligent fuzzy logic controller (FLC) in both step-down-up mode. Simulation outcome and investigation of proposed converter shows that over shoot, settling time of PIC in step-up mode is $0.50 \%$ and 0.04 seconds whereas the for FIC it is reduced to $0.186 \%$ and 0.003 seconds, similarly in step-down mode in PIC it is $0.129 \%$ and 0.06 seconds and in FIC its reduced to $0.115 \%$ and 0.008 seconds where fuzzy logic control performance is greatly improved and superior.

\section{REFERENCES}

1. D. Maksimovic and S. Cuk, "General properties and synthesis of PWM DC-to-DC converters," in Proc. IEEE Power Electron. Spec. Conf., 1989, pp. 515-525.

2. D. Maksimovic and S. Cuk, "Switching converters with wide DC conversion range," IEEE Trans. Power Electron., vol. 6, no. 1, pp. 151-157, Jan. 1991.

3. G. Moschopoulos, "Quadratic power conversion for industrial applications," in Proc. 25th Annu. IEEE Appl. Power Electron. Conf. Expo., 2010, pp. 1320-1327.

4. X. L. Wei, K. M. Tsang, and W. L. Chan, "Non-linear PWM control of single-switch quadratic buck converters using internal model," IET Power Electron., vol. 2, no. 5, pp. 475-483, Sep. 2009.

5. J. A. M. Saldana, J. L. Ramos, E. E. C. Gutierrez, and M. G. O. Lopez, "Average current-mode control scheme for a quadratic buck converter with a single switch," IEEE Trans. Power Electron., vol. 23, no. 1, pp. 485-490, Jan. 2008.

6. J. J. Chen, B. H. Huang, C. M. Kung, W. Y. Tai, and Y. S. Hwang, "A new single-inductor quadratic buck converter using average-currentmode control without slope-compensation," in Proc. 5th IEEE Conf. Ind. Electron. Appl., Jun. 2010, pp. 1082-1087.

7. J.A.M. Saldana, R. L. Palomo, and E. P. Hernandez, "Parameters selection criteria of proportional-integral controller for a quadratic buck converter," IET Power Electron., vol. 7, no. 6, pp. 1527-1535, Jun. 2014.

8. A. Ayachit and M. K. Kazimierczuk, "Open-loop small signal transfer functions of the quadratic buckPWMDC-DC converter in CCM," in Proc. 40th Annu. Conf. IEEE Ind. Electron. Soc., Nov. 2014, pp. 1643-1649.

9. J. L. Ramos, M. G. O. Lopez, L. H. D. Saldierna, and J. A. M. Saldana, "Switching regulator using a quadratic boost converter for wide DC conversion ratios," IET Power Electron., vol. 2, no. 5, pp. 605-613, Sep. 2009.

10. J. A. M. Saldana, R. L. Palomo, E. P. Hernandez, and J. L. G. Martinez, "Modelling and control of aDC-DCquadratic boost converter withR2P2 ," IET Power Electron., vol. 7, no. 1, pp. 11-22, Jan. 2014.

11. O. L. Santos, L. M. Salamero, G. Garcia, H. V. Blavi, and T. S. Polanco, "Robust sliding-mode control design for a voltage regulated quadratic boost converter," IEEE Trans. Power Electron., vol. 30, no. 4, pp. 2313- 2327, Apr. 2015.

12. M. A. A. Saffar, E. H. Ismail, and A. J. Sabzali, "High efficiency quadratic boost converter," in Proc. 27th Annu. IEEE Appl. Power Electron. Conf. Expo., 2012, pp. 1245-125

13. Pedro Martín García-Vite; Julio C. Rosas-Caro ; Ana Lidia Martínez-Salazar ; Jose de Jesus Chavez ; Antonio Valderrábano-González ; Victor M. Sánchez-Huerta, "Quadratic buck-boost converter with reduced input current ripple and wide conversion range," IET Power Electronics 2019 Volume: 12, Issue: 15 ,Journal Article, IET.

\section{Published By:}

Blue Eyes Intelligence Engineering \& Sciences Publication 
14. S. Miao, F. Wang, and X. Ma, "A new transformerless buck-boost converter with positive output voltage," IEEE Trans. Ind. Electron., vol. 63, no. 5, pp. 2965-2975, May 2016.

15. Vitor Fern ao Pires , Senior Member, IEEE, Daniel Foito, and Armando Cordeiro "A DC-DC Converter With Quadratic Gain and Bidirectional Capability for Batteries/Supercapacitors" IEEE TRANSACTIONS ON INDUSTRY APPLICATIONS.

16. Jörg Dannehl, Student Member, IEEE, Friedrich Wilhelm Fuchs, Senior Member, IEEE, Steffan Hansen, Member, IEEE, and Paul Bach Thøgersen, Senior Member, IEEE "Investigation of Active Damping Approaches for PI-Based Current Control of Grid-Connected Pulse Width Modulation Converters With LCL Filters" IEEE transactions on industry applications, vol. 46, no. 4, july/august 2010.

17. Ali Jaafar, Aya Alawieh, R. Ortega, Emmanuel Godoy, and Pierre Lefranc "PI Stabilization of Power Converters with Partial State Measurements" IEEE transactions on control systems technology, vol. 21, no. 2, march 2013.

18. Meriem Merai, Mohamed Wissem Naouar, Member, IEEE, Ilhem Slama-Belkhodja, Member, IEEE, and Eric Monmasson , Senior Member, IEEE "An Adaptive PI Controller Design for DC-Link Voltage Control of Single-Phase Grid-Connected Converters" IEEE Transactions On Industrial Electronics, Vol. 66, No. 8, August 2019.

19. Zengshi Chen "PI and Sliding Mode Control of a Cuk Converter" IEEE Transactions on Power Electronics, Vol. 27, No. 8, august 2012.

20. Liping Guo, Member, IEEE, John Y. Hung, Senior Member, IEEE, and R. M. Nelms, Fellow, IEEE "Evaluation of DSP-Based PID and Fuzzy Controllers for DC-DC Converters" IEEE Transactions on Industrial Electronics, Vol. 56, No. 6, JUNE 2009.

21. Abdul R. Ofoli, Student Member, IEEE, and Ahmed Rubaai, Senior Member, IEEE "Real-Time Implementation of a Fuzzy Logic Controller for Switch-Mode Power-Stage DC-DC Converters" IEEE Transactions on Industry Applications, Vol. 42, No. 6 , November/December 2006.

22. Wing-Chi So, Member, IEEE, Chi K. Tse, Member, IEEE, and Yim-Shu Lee "Development of a Fuzzy Logic Controller for DC-DC Converters: Design, Computer Simulation, and Experimental Evaluation” IEEE Transactions on Power Electronics, Vdl 11, No. 1, January 1996.

23. Alexander G. Perry, Guang Feng, Member, IEEE, Yan-Fei Liu, Senior Member, IEEE, and Paresh C. Sen, Fellow, IEEE “A Design Method for PI-like Fuzzy Logic Controllers for DC-DC Converter" IEEE Transactions on Industrial Electronics, Vol. 54, No. 5, October 2007.

24. Ahmad El Khateb, Member, IEEE, Nasrudin Abd Rahim, Senior Member, IEEE, Jeyraj Selvaraj, and Mohammad Nasir Uddin, Senior Member, IEEE "Fuzzy-Logic-Controller-Based SEPIC Converter for Maximum Power Point Tracking" IEEE Transactions On Industry Applications, Vol. 50, No. 4, July/August 2014.

25. Rong-Jong Wai, Senior Member, IEEE, and Li-Chung Shih “Adaptive Fuzzy-Neural-Network Design for Voltage Tracking Control of a DC-DC Boost Converter" IEEE Transactions on Power Electronics, Vol. 27, No. 4, April 2012.

26. Juan Luis Agorreta, Luis Reinaldos, Roberto González, Mikel Borrega, Julián Balda, and Luis Marroyo, Member, IEEE"Fuzzy Switching Technique Applied to PWM Boost Converter Operating in Mixed Conduction Mode for PV Systems" IEEE Transactions on Industrial Electronics, Vol. 56, No. 11, November 2009.

27. Thodoris L. Kottas , (Student Member, Ieee), Athanasios D. Karlis, (Senior Member, Ieee), And Yiannis S. Boutalis, (Member, Ieee) Department of Electrical and Computer Engineering, Democritus University of Thrace, 67100 Xanthi, Greece "A Novel Control Algorithm for DC Motors Supplied by PVs Using Fuzzy Cognitive Networks" Received January 11, 2018, accepted February 28, 2018, date of publication May 4, 2018, date of current version May 24, 2018.

28. Mohammed Masum Siraj Khan, Student Member, IEEE, Md Omar Faruque, Senior Member, IEEE, and Alvi Newaz, Student Member, IEEE "Fuzzy Logic Based Energy Storage Management System for MVDC Power System of All Electric Ship" IEEE Transactions On Energy Conversion, Vol. 32, No. 2, June 2017.

\section{AUTHORS PROFILE}

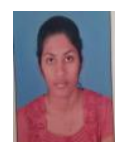

Lahari S pursuing MTech in Power Electronics from Dayananda Sagar College of Engineering, Bangalore, Karnataka. Received the B.E degree in Electronics and Communication engineering from Bangalore Institute of Technology, Bangalore India. Her interests include control systems and renewable energy sources.

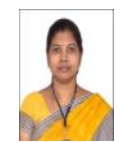

Dr. Dhanalakshmi.R received Ph.D. from Anna University, Chennai, TamilNadu. She is working as a Professor in the Department of Electrical and Electronics Engineering, Dayananda Sagar College of Engineering, Bangalore. She has published a good number of research papers in reputed journals. Her research interest includes Renewable Energy conversion and control system, Power Electronics, Artificial Intelligent techniques and Optimization techniques.

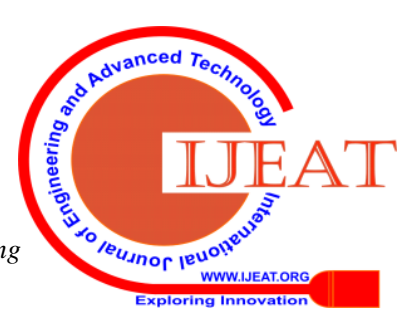

